\title{
DAYA SAING UMKM MELALUI PERSPEKTIF CORE PRODUCT DAN SUPPLEMENTARY SERVICE
}

\author{
Oleh : Imam Nuryanto ${ }^{1}$ dan Ida Farida ${ }^{2}$ \\ Staf Pengajar Fakultas Ekonomi dan Bisnis Universitas Dian Nuswantoro \\ imam.nuryanto@dsn.dinus.ac.id ${ }^{1}$, ida.farida@dsn.dinus.ac.id ${ }^{2}$ \\ Jl. Nakula I No. 5-11 Semarang
}

\begin{abstract}
Abstrak
Usaha Mikro Kecil dan Menengah (UMKM) memiliki peran penting bagi perekonomian Indonesia, namun daya saing UMKM masih rendah, salah satu penyebabnya adalah lemahnya kualitas pelayanan. Tujuan penelitian ini adalah untuk mengetahui pengaruh kualitas pelayanan "the flower of service" terhadap loyalitas konsumen. Objek penelitian adalah UMKM CENTER Jawa Tengah. Penentuan sampel dengan metode purpossive sampling, sebanyak 100 responden. Analisis menggunakan Regresi Linier Sederhana. Hasil dari penelitian ini membuktikan dan memberi kesimpulan bahwa: kualitas pelayanan "the flower of service" berpengaruh positif dan signifikan terhadap loyalitas konsumen. UMKM CENTER Jawa Tengah memiliki 8 kelopak "the flower of service" dengan nilai score $\geq 3,41$, artinya UMKM memiliki daya saing optimal dan layanan jasa yang baik, nilai rincian sebagai berikut : information (4,17), consultation (4,29), ordertaking (4,08), hospitality (4,2), safekeeping (4,18), exception (4,21), billing (4,04) dan payment (4,09). Dari kelopak indikator tersebut, nilai score tertinggi adalah 4,29 yaitu consultation, sedangkan nilai score terendah adalah billing.
\end{abstract}

Kata Kunci: UMKM, kualitas pelayanan (the flower of service) dan loyalitas konsumen.

\section{Pendahuluan}

\subsection{Latar Belakang Masalah}

Di ASEAN, kontribusi UMKM Indonesia terhadap rantai pasok produksi global hanya sedikit lebih tinggi dibandingkan dengan Brunei, Laos, Myanmar, dan Kamboja. Kontribusi tertinggi sektor UMKM terhadap rantai pasok produksi global mencapai 2,7 persen. Padahal, ASEAN berkontribusi 9,3 persen terhadap rantai pasok produksi global pada periode 2009-2013. Kontribusi sektor UMKM terhadap ekspor Indonesia tahun 2015 hanya 15,8 persen, jauh lebih kecil dibandingkan dengan negara-negara sekawasan di Asia Tenggara. Kontribusi sektor UMKM Thailand terhadap ekspor 29,5 persen dan Filipina 20 persen. Di tingkat global, kontribusi sektor UMKM Jerman terhadap ekspor mencapai 55,9 persen dan Jepang sekitar 53,8 persen (http://www.kemenperin.go.id).

Daya Saing UMKM perlu ditingkatkan agar dapat bersaing, seiring dengan berlakunya Masyarakat Ekonomi ASEAN (MEA) 2015. Penelitian ini didasarkan pada pemikiran, bahwa UMKM merupakan andalan penopang perekonomian daerah. Usaha Mikro Kecil dan Menengah (UMKM) memegang peranan penting bagi perekonomian Indonesia, namun daya saing UMKM masih rendah, salah satu penyebab rendahnya daya saing UMKM adalah lemahnya kualitas pelayanan. Lovelock dkk (2010) mengembangkan suatu model pengembangan konsep jasa yang dikenal dengan "the flower of service". Terdiri atas dua bagian, yaitu produk inti (core product) dan layanan / jasa pelengkap (supplementary service) yang dapat menambah Daya Saing bagi UMKM tersebut. Tambunan (2008) menyatakan bahwa meskipun ukuran Daya Saing UMKM beragam, identifikasi mengenai daya saing UMKM perlu mencakup tiga karakteristik yaitu potensi, proses dan kinerja. Telah banyak studi yang dilakukan mengenai daya saing UMKM dengan hasil yang bervariasi. Salah satu yang terpenting adalah hasil penelitian dari Man, Lau \& Chan (2002:123-142) yang mencoba untuk menganalisis tingkat Daya Saing UMKM dengan menggabungkan antara konsep daya saing dan kompetensi kewirausahaan. 
Menurut Gal (2010), peningkatan daya saing dapat diukur dari sisi kinerjanya. Berdasarkan model dari Buckely dkk (1998:175-200), daya saing dianggap sebagai proses yang berkelanjutan, tidak hanya kinerja yang dihasilkan, tetapi juga proses untuk melakukannya. Li (2011) menyatakan faktor kompetitif menjadi tingkat pertama, kriteria sebagai tingkat kedua dan atribut sebagai tingkat ketiga. Hunter dan Lean (2014:179-190) menambahkan bahwa karakter entrepreneurial leadership diperlukan oleh seorang pemilik UMKM untuk memimpin usahanya. Karakter yang dinyatakan berperan penting adalah ambisius, berorientasi pada kinerja, dan visioner.

Daya saing yang tinggi juga sangat diperlukan dalam kondisi bersaing dengan pasar global seperti dengan adanya implementasi Masyarakat Ekonomi Asean. Susilo (2012) menyatakan bahwa kunci utamanya adalah UMKM itu sendiri khususnya pemilik UMKM dengan dukungan para pekerjanya. Donald dkk (2016) menyatakan untuk meningkatkan daya saing, UMKM harus memiliki kemampuan berkompetisi. Untuk mencapai kinerja yang sangat baik, UMKM harus mempertimbangkan beberapa faktor yang mempengaruhi kinerja. Dari latar belakang masalah diatas maka peneliti tertarik untuk meneliti Daya Saing UMKM dengan konsep jasa "the flower of service". Terdiri atas dua bagian, yaitu produk inti (core Product) dan layanan / jasa pelengkap (supplementary Service) yang mengacu pada 8 indikator yaitu information, consultation, ordertaking, hospitality, safekeeping, exception, billing dan payment.

\subsection{Rumusan Masalah}

1. Bagaimana tingkat daya saing UMKM melalui "the flower of service" (core product) dan (supplementary service)?

2. Bagaimanakah pengaruh service quality terhadap loyalitas konsumen UMKM CENTER Jawa Tengah ?

\subsection{Tujuan Penelitian}

1. Mengetahui tingkat daya saing UMKM melalui "the flower of service" (core product) dan (supplementary service).

2. Menganalisis pengaruh service quality terhadap loyalitas konsumen UMKM CENTER Jawa Tengah.

\section{Kajian Pustaka}

\subsection{Pemasaran Jasa}

Jasa sering dipandang sebagai fenomena yang rumit. Jasa pada dasarnya merupakan semua aktivitas ekonomi yang hasilnya tidak merupakan produk dalam bentuk fisik, yang umumnya dikonsumsi pada saat yang sama dengan waktu dihasilkan dan memberi nilai tambah (Lupiyoadi, 2013:6)

\subsection{Loyalitas Konsumen}

Abdullah (2016:195) loyalitas kosumen adalah kesetiaan pelanggan terhadap produk barang/jasa yang biasa dikonsumsinya. Loyalitas konsumen perlu dijaga oleh pemasar agar konsumen tidak beralih ke produk lain. Kesetiaan seorang konsumen adalah orang yang akan kembali lagi karena merasa terpenuhi kebutuhannya dan pasti perusahaan tersebut akan mendapatkan untung (Cuff dan Halsey, 2016:7).

\subsection{The Flower of Service}

Lovelock dkk (2010) mengembangkan suatu model pengembangan konsep jasa (service concept) yang dikenal dengan "the flower of service". Terdiri atas dua bagian, yaitu produk inti (core product) dan layanan/ jasa pelengkap (supplementary service) yang dapat menambahkan nilai bagi UMKM tersebut. Model "the flower of service" mengemukakan bahwa produk inti dikelilingi oleh delapan jenis jasa pelengkap. Terdiri atas dua bagian, yaitu produk inti (core product) dan layanan / jasa pelengkap (supplementary service) yang mengacu pada 8 indikator yaitu information, consultation, ordertaking, hospitality, safekeeping, exception, billing dan payment.

\subsection{Pengembangan Hipotesis}


Hipotesis yang diajukan dalam penelitian ini adalah :

Ho = Tidak ada pengaruh yang signifikan antara service quality dan customer loyalty.

$\mathrm{Ha}=$ Terdapat pengaruh yang signifikan antara service quality dan customer loyalty.

\subsection{Kerangka Konseptual}

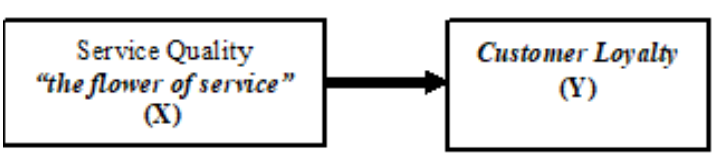

\section{Metode Penelitian}

\subsection{Populasi dan Sampel Penelitian}

Populasi adalah sebagai suatu kumpulan subyek, variabel, konsep, atau fenomena. Kita dapat meneliti setiap anggota populasi untuk mengetahui sifat populasi yang bersangkutan (Morissan, 2012:19). Dalam penelitian ini adalah warga Kota Semarang yang pernah melakukan pembelian di UMKM Center Jawa Tengah. Jumlah populasi warga yang ada di Kota Semarang pada tahun 2016 sebanyak 1.765.836 juta jiwa (dispendukcapil.semarangkota.go.id). Sampel diambil secara purposive sampling yaitu teknik sampling berdasarkan kriteria (Sugiyono, 2014:85). Untuk menentukan besarnya sampel maka bisa menggunakan rumus slovin dalam Darwati (2016) sebagai berikut : $\mathrm{n}=\left(\mathrm{N} / 1+\mathrm{N} \cdot \mathrm{e}^{2}\right)$, Dimana $\underline{\mathrm{n}}$ adalah ukuran sampel dan $\underline{\mathrm{N}}$ adalah ukuran populasi, sedangkan $\underline{\mathrm{e}}$ adalah prosentase kelonggaran dalam penelitian. Dari perhitungan didapat sampel sebesar 99,9 apabila dibulatkan banyaknya sampel sebesar 100 responden.

Syarat kriteria sampel : Konsumen yang pernah membeli atau menggunakan jasa di UMKM Center Jawa Tengah.

\subsection{Teknik Analisis}

Penelitian ini menggunakan teori konsep pemasaran jasa "the flower of service" dengan mengacu pada 8 indikator yaitu information, consultation, ordertaking, hospitality, safekeeping, exception, billing dan payment. Analisis yang digunakan dalam penelitian ini menggunakan Regresi Linier Sederhana.

\section{Hasil Analisis}

\begin{tabular}{|c|c|c|c|}
\hline \multicolumn{4}{|c|}{ Correlations } \\
\hline & & FOS & CUST \\
\hline \multirow[t]{2}{*}{ Pearson Correlation } & FOS & 1.000 & .867 \\
\hline & CUST & .867 & 1.000 \\
\hline \multirow[t]{2}{*}{ Sig. (1-tailed) } & FOS & & .000 \\
\hline & CUST & .000 & \\
\hline \multirow[t]{2}{*}{$N$} & FOS & 100 & 100 \\
\hline & CUST & 100 & 100 \\
\hline
\end{tabular}

\section{Keterangan :}

1. Dari tabel Correlations tersebut, dapat diketahui bahwa nilai $\boldsymbol{r}$ hitung adalah 0,867 Angka ini menunjukkan korelasi yang kuat antara variabel $\mathbf{X}$ (the flower of service) dan variabel $\mathbf{Y}$ (customer loyalty).

2. Sig. (1-tailed) $=0,000$ menunjukkan hubungan yang signifikan karena $\mathbf{0 , 0 0 0 < 0 , 0 5}$ dimana 0,05 merupakan taraf signifikan.

3. $\mathbf{N}$ merupakan jumlah data dari masingmasing variabel.

\begin{tabular}{|l|c|c|c|c|}
\hline Model & \multicolumn{1}{|c|}{ M } & R Square & $\begin{array}{c}\text { Adjusted R } \\
\text { Square }\end{array}$ & $\begin{array}{c}\text { Std. Error of the } \\
\text { Estimate }\end{array}$ \\
\hline 1 & $.867^{\mathrm{a}}$ & .752 & .749 & .36608 \\
\hline
\end{tabular}
a. Predictors: (Constant), CUST
b. Dependent Variable: FOS

\section{Keterangan :}

1. $\mathbf{R}$ merupakan koefisien korelasi dimana dalam kasus ini besarnya $\mathrm{R}$ adalah 0,867

2. $\mathbf{R}$ Square merupakan koefisien determinasi. Dalam kasus ini, besar $\mathrm{R}$ Square $\left(\mathrm{R}^{2}\right)$ adalah $0,752=75,2 \%$. Artinya, besarnya pengaruh variabel $\mathrm{X}$ terhadap Y adalah $75,2 \%$ dan besarnya variabel lain yang memengaruhi variabel Y adalah sebesar 24,8\%)

3. Adjusted R Square merupakan nila $\mathrm{R}^{2}$ yang disesuaikan. 
4. Std. Error of the Estimation merupakan ukuran kesalahan standar dari penaksiran.

\begin{tabular}{|c|c|c|c|c|c|c|}
\hline \multicolumn{7}{|c|}{ ANOVA $^{b}$} \\
\hline Mod & & Sum of Squares & $d f$ & Mean Square & $\mathrm{F}$ & Sig. \\
\hline 1 & Regression & 39.792 & 1 & 39.792 & 296.930 & $.000^{\mathrm{s}}$ \\
\hline & Residual & 13.133 & 98 & .134 & & \\
\hline & Total & 52.926 & 99 & & & \\
\hline
\end{tabular}

a. Predictors: (Constant), CUST

b. Dependent Variable: FOS

\section{Keterangan :}

Tabel ANOVA ini menampilkan nila $\boldsymbol{F}$ hitung, yaitu sebesar 296.930.

\begin{tabular}{|c|c|c|c|c|c|c|}
\hline \multicolumn{7}{|c|}{ Coefficients $^{\mathrm{a}}$} \\
\hline \multirow[b]{2}{*}{ Model } & & \multicolumn{2}{|c|}{ Unstandardized Coefficients } & $\begin{array}{l}\text { Standardized } \\
\text { Coefficients }\end{array}$ & \multirow[b]{2}{*}{$t$} & \multirow[b]{2}{*}{ Sig. } \\
\hline & & B & Std. Error & Beta & & \\
\hline 1 & (Constant) & .755 & .201 & & 3.762 & .000 \\
\hline & CUST & .809 & .047 & .867 & 17.232 & .000 \\
\hline
\end{tabular}

\section{Keterangan :}

Persamaan Regresi $\mathbf{Y}=\mathbf{0 , 7 5 5}+\mathbf{0 , 8 0 9} \mathbf{X}$ menyatakan bahwa jika tidak ada kenaikan nilai dari variabel $\mathbf{X}$, nilai variabel $\mathbf{Y}$ adalah 0,755. Koefisien regresi sebesar $\mathbf{0 , 8 0 9}$ menyatakan bahwa setiap penambahan satu nilai pada variabel $\mathbf{X}$ akan memberikan kenaikan skor sebesar $\mathbf{0 , 8 0 9}$.

Normal P-P Plot of Regression Standardized Residual

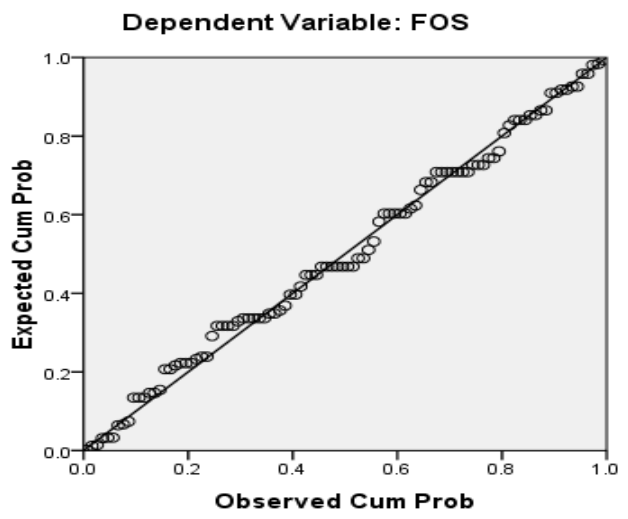

\section{Interpretasi Hasil}

\subsection{Hipotesis}

Ho : Tidak ada pengaruh yang signifikan antara variabel $\mathrm{X}$ dan variabel $\mathrm{Y}$.

$\mathrm{Ha}$ : Terdapat pengaruh yang signifikan antara variabel $\mathrm{X}$ dan variabel $\mathrm{Y}$.

\subsection{Dasar pengambilan Keputusan.}

1. Jika nilai probabilitas lebih kecil daripada atau sama dengan nilai probabilitas Sig, $\quad(0,05 \leq$ Sig. $), \quad$ Ho diterima (Ha ditolak). Artinya, tidak signifikan.

2. Jika nilai probabilitas lebih besar daripada atau sama dengan nilai probabilitas Sig. (0,05 $\geq$ Sig.), Ho ditolak (Ha diterima). Artinya, signifikan.

Hasil uji signifikansi pada tabel ANOVA menunjukkan nilai Sig. Sebesar 0,000. Jika dibandingkan dengan $\alpha=0,05$, nilai Sig. Lebih kecil daripada $\alpha$ (Sig $\leq \alpha)$, yaitu $0,000 \leq 0,05$. Artinya, Ho ditolak dan $\mathrm{Ha}$ diterima. Dengan demikian, hal ini menunjukkan bahwa variabel $\mathrm{X}$ berpengaruh secara signifikan terhadap variabel Y.

\section{Kesimpulan dan Saran}

Analisis yang digunakan dalam penelitian ini menggunakan Regresi Linier Sederhana. Hasil dari penelitian ini membuktikan dan memberi kesimpulan bahwa: Service Quality "the flower of service" berpengaruh positif dan signifikan terhadap loyalitas konsumen. Persamaan Regresi $\mathbf{Y}=\mathbf{0 , 7 5 5}+\mathbf{0 , 8 0 9} \mathrm{X}$ menyatakan bahwa jika tidak ada kenaikan nilai dari variabel $\mathbf{X}$, nilai variabel $\mathbf{Y}$ adalah $\mathbf{0 , 7 5 5}$. Koefisien regresi sebesar $\mathbf{0 , 8 0 9}$ menyatakan bahwa setiap penambahan satu nilai pada variabel $\mathbf{X}$ akan memberikan kenaikan score sebesar $\mathbf{0 , 8 0 9}$. UMKM CENTER Jawa Tengah memiliki 8 kelopak "the flower of service" dengan nilai score $\geq 3,41$, hal ini mengindikasikan bahwa UMKM memiliki daya saing optimal dan layanan jasa yang baik, dengan rincian nilai sebagai berikut :

information (4,17), consultation $(4,29)$, ordertaking (4,08), hospitality $(4,2)$, safekeeping (4,18), exception $(4,21)$, 
billing $(4,04)$ dan payment $(4,09)$. Dari kelopak indikator tersebut, nilai score tertinggi adalah 4,29 yaitu consultation, sedangkan nilai score terendah adalah billing. Sehingga disarankan untuk mempertahankan kualitas layanan dan meningkatkan nilai terendah dari kelopak "the flower of service".

\section{DAFTAR PUSTAKA}

Abdullah, Ma'aruf. 2016. Manajemen Komunikasi Periklanan. Edisi 1. Asjawa Pressindo. Yogyakarta

Buckley, P.J., Pass, C.L. \& Prescott, K. 1988. Measures of International competitiveness: a critical survey. Journal of Marketing Management, 4(2), 175-200.

Cuff, Kathy, dan Vicki Halsey. 2016. Legendary Service. Edisi 1. Menuju Insan Cemerlang. Surabaya

Darmawanti 2016. Pengaruh kualitas layanan terhadap Loyalitas Konsumen dalam Memakai jasa Percetakan CV Rahmat Nur di Samarinda. Ejournal ilmu Administrasi Bisnis. Vol.4 No.1, p: 157-171

Donald Crestofel Lantu, Mochamad Sandy Triady, Ami Fitri Utami, Achmad Ghazali 2016. Pengembangan Model Peningkatan Daya Saing UMKM di Indonesia : Validasi Kuantitatif Model. Jurnal Manajemen Teknologi, 15(1), 2016, 77-93 http://journal.sbm.itb.ac.id

Gál, A. N. 2010. Competitiveness of small and medium sized enterprises - a possible analytical framework. Diunduh tanggal 12 April 2012 dari http://heja.szif.hu/ECO/ECO100115-A/eco100115a.pdf.

Li, V. 2011. The methodology to assess the competitiveness of real estate developers in China. Queensland University of Technology.

Lovelock Christopher, Jochen Wirtz \& Jacky Mussry 2010. Pemasaran Jasa - Manusia, Teknologi, Strategi
Perspektif Indonesia. Penerbit Erlangga

Man T. W. Y; Lau, T., \& Chan, K. F. 2002. The competitiveness of small and medium enterprises - $\mathrm{A}$ conceptualization with focus on entrepreneurial competencies. Journal of Business Venturing, 17(2), 123-142.

Morissan. 2012. Metode Penelitian Survei. Kencana. Jakarta

Rambat Lupiyoadi. 2013. Manajemen Pemasaran Jasa - Berbasis Kompetensi. Penerbit Salemba Empat. Jakata

Susilo, Y., Sri. 2012. Strategi Meningkatkan Daya Saing Umkm Dalam Menghadapi Implementasi CAFTA dan MES. Buletin Ekonomi. ISSN 1410-2293.

Sumber

Internet http://www.kemenperin.go.id/artikel/ 14200/Kontribusi-UMKM-Naik, Diunduh tanggal 20 Juni 2017

Sumber Internet http:// www.dispendukcapil.semarangkota.g o.id. Populasi Kota Semarang. Diunduh tanggal 20 Juni 2017

Sugiyono. 2014. Metode Penelitian Kuantitas dan R \& D. Alfabeta. Bandung

Tambunan, T. T. H. 2008. Ukuran Daya Saing Koperasi dan UKM. Badan Perencanaan Pembangunan Nasional. 2008. 